\title{
Appearance of Opsin-containing Vesicles as Rhabdomeric Precursors and Their Incorporation into the Rhabdom around Dusk in the Compound Eye of the Crab, Hemigrapsus sanguineus
}

Author(s): Atsuko Matsushita, Kentaro Arikawa, Eisuke Eguchi

Source: Zoological Science, 16(1):25-34. 1999.

Published By: Zoological Society of Japan

DOI: http://dx.doi.org/10.2108/zsj.16.25

URL: http://www.bioone.org/doi/full/10.2108/zsj.16.25

BioOne (www.bioone.org) is a nonprofit, online aggregation of core research in the biological, ecological, and environmental sciences. BioOne provides a sustainable online platform for over 170 journals and books published by nonprofit societies, associations, museums, institutions, and presses.

Your use of this PDF, the BioOne Web site, and all posted and associated content indicates your acceptance of BioOne's Terms of Use, available at www.bioone.org/page/terms_of_use.

Usage of BioOne content is strictly limited to personal, educational, and non-commercial use. Commercial inquiries or rights and permissions requests should be directed to the individual publisher as copyright holder. 


\title{
Appearance of Opsin-containing Vesicles as Rhabdomeric Precursors and Their Incorporation into the Rhabdom around Dusk in the Compound Eye of the Crab, Hemigrapsus sanguineus
}

\author{
Atsuko Matsushita ${ }^{1}$, Kentaro Arikawa $^{1,2 *}$ and Eisuke Eguchi ${ }^{1}$ \\ ${ }^{1}$ Graduate School of Integrated Science, Yokohama City University, Yokohama 236-0027, and \\ ${ }^{2}$ PRESTO, Japan Science and Technology Corporation, Japan
}

\begin{abstract}
This paper presents immunocytochemical, freeze-fracture, and fine-structural evidence for the hypothesis that the precursors of the rhabdomeric membranes are vesicles in the photoreceptors of the crab Hemigrapsus sanguineus. The number of vesicles starts to increase in the photoreceptor cell body at midday and peaks at approximately one hour before light-off. The vesicles move toward the rhabdom: they almost disappear from the cell body within the first hour after light-off. As they move, the rhabdom area increases. Electron microscopic immunocytochemistry and freeze-fracture EM revealed that the vesicles contain the visual pigment opsin as an integral membrane protein. Based on detailed observation at the microvillar base by conventional electron microscopy, we present a model of how the vesicles are incorporated into the rhabdom to elongate the rhabdomeric microvilli.
\end{abstract}

\section{INTRODUCTION}

The retinal photoreceptor is a highly polarized neuron with a photoreceptive structure, a cell body, and an axon. The photoreceptive structure of arthropod and molluscan photoreceptors is called the rhabdom. It comprises closely packed microvilli that bear visual pigment molecules (generically these are rhodopsins) as integral membrane proteins.

Microvilli are not static structures: turnover through processes of membrane removal and addition is continuous (for reviews see Blest, 1980; Waterman, 1982; Schwemer, 1985; Blest, 1988). These turnover processes are controlled by ambient light conditions (Eguchi and Waterman, 1967; White, 1967; Blest et al., 1993; Blest and Stowe, 1997) though they are also modulated by factors such as the biological clock and the supply of material for rhodopsin biosynthesis (Barlow et al., 1980; White and Bennet, 1992; Ozaki et al., 1993; Huber et al., 1994; Stark and White, 1996).

Membrane is removed from the rhabdom by pinocytosis at the microvillar base. The pinocytotic vesicles are collected to form multivesicular bodies (MVBs) that are finally degraded in the photoreceptor cell itself (Eguchi and Waterman, 1976). (Exceptions are the tipulid flies, in which membrane is removed by extracellular shedding at the microvillar tips (Williams and Blest, 1980)). Compared with the removal process, little is

\footnotetext{
* Corresponding author: Tel. +81-45-787-2212; FAX. +81-45-787-2212.

E-mail: arikawa@yokohama-cu.ac.jp
}

known about the processes of membrane synthesis and rhabdom morphogenesis. New membranes are thought to be synthesized, probably together with rhodopsins, in rough-surfaced endoplasmic reticulum ( $\mathrm{rER}$ ) and then delivered to the microvillar base to be incorporated. However, the intermediaries between synthesis and incorporation have not been rigorously studied. What is the anatomical appearance of the intermediaries, i.e., rhabdom precursors? How are they formed and incorporated into the rhabdoms? Although number of fragmentary observations in this respect are made in various species (Itaya, 1976; Stowe, 1980; Robles et al., 1984; Suzuki and Hirosawa, 1991), the picture of the process had been far from complete.

Here we addressed these questions in photoreceptor cells of the grapsid crab, Hemigrapsus sanguineus. The rhabdom of this species drastically changes its volume between day and night as in other decapod crustaceans (Nässel and Waterman, 1979; Stowe, 1980; Toh, 1987; Toh, 1990b). The rhabdom of $H$. sanguineus at midnight is about 8 times larger than at midday: this is due to vigorous turnover of the membrane (Arikawa et al., 1987). We recently found that vesicles accumulate in the photoreceptor cell body when the rhabdom synthesis is experimentally inhibited around dusk (Matsushita and Arikawa, 1996). This implies that the vesicles are the precursors of the rhodopsin-containing rhabdomeric membrane. Therefore, we carried out electron microscopic immunocytochemistry for opsin, the protein moiety of rhodopsin, and found that the vesicles were immunoreactive to anti-crab op$\sin$. We also confirmed that the vesicles actually move toward 
the rhabdom around dusk. Furthermore, we carefully observed the microvillar base during rhabdom morphogenesis, and propose a model of how the vesicles are incorporated into the rhabdom. The present results all support the hypothesis that the vesicles are the precursors of the rhabdomeric membrane.

\section{MATERIALS AND METHODS}

\section{Animals}

Grapsid crabs, Hemigrapsus sanguineus (carapace width $=20$ $30 \mathrm{~mm}$ ), collected from rocky shores at Nojima park (Yokohama City, Japan) were kept in a LD $12 \mathrm{hr}: 12 \mathrm{hr}$ regime (light period from 4:00 to 16:00, light intensity approximately 200 lux from fluorescent lamps) for at least 1 week at $25^{\circ} \mathrm{C}$ prior to the experiment.

\section{Fine structure and biometrical analyses (conventional EM)}

The eyes were prefixed with a phalloidin-containing fixative (10 $\mu \mathrm{M}$ phalloidin, $2 \%$ paraformaldehyde, $2 \%$ glutaraldehyde, $1 \mathrm{mM} \mathrm{MgCl}_{2}$, $1 \mathrm{mM}$ EGTA, and $0.1 \%$ saponin in $0.1 \mathrm{M}$ PIPES; $\mathrm{pH} 7.2$ ) for $2 \mathrm{hr}$ at room temperature $\left(25-27^{\circ} \mathrm{C}\right)$ and further fixed overnight in the fixative at $4^{\circ} \mathrm{C}$. After washing with PIPES buffer solution, the eyes were postfixed with $2 \% \mathrm{OsO}_{4}$ in PIPES buffer for $1.5-2 \mathrm{hr}$ at room temperature, then dehydrated with an acetone series, infiltrated, and embedded in Epon. Silver-gray sections (60-70 nm thick) cut with a diamond knife were double stained with uranyl acetate and lead citrate, and examined with a JEOL 1200EX electron microscope.

The biometrical analysis was done on electron micrographs of a transverse section of ommatidia at the level immediately below the photoreceptor nuclei. Rhabdom areas were measured and the density of vesicles in the cell body was quantified (the total number of vesicles was divided by the transversely sectioned area of the cell body) for samples at different times of the day. At least two individuals were used in each sample. Data of an individual were collected from one section only to avoid collecting data from the same ommatidia in consecutive sections.

\section{Antiopsin preparation}

To produce antibody for the visual pigment opsin of $H$. sanguineus, we first synthesized an 11 amino acid peptide (Glu-LysAsp-Pro-Asn-Asp-Val-Glu-Glu-Asn-Gln) with a sequence identical to a region near the C-terminal of Hemigrapsus Rh-1 (Sakamoto et al., 1996). The polypeptide, named ' $1 C$ ', was linked to a Keyhole limpet hemocyanin ( $\mathrm{KLH}$, Calbiochem-Novabiochem Corp.) as the linkage protein, and then injected into a rat. The antiserum $(\alpha 1 \mathrm{C})$ was used for both immunoblot and immunocytochemistry.

\section{Verification of antibody specificity (immunoblot analysis)}

Specificity of the antibody to the crab retinal tissue was confirmed by immunoblot analysis. Retinal proteins were separated by electrophoresis in a 12\% SDS-polyacrylamide slab gel (Laemmli, 1970). For immunoblotting, the proteins were electrophoretically transferred onto polyvinylidene difluoride membranes (PVDF, Millipore) using an SDScontaining buffer $(0.02 \%$ SDS, $25 \mathrm{mM}$ Tris, $192 \mathrm{mM}$ glycine and $20 \%$ methanol, Ozaki et al., 1993). The blot was first blocked with $1 \%$ skimmed milk in TBS $(150 \mathrm{mM} \mathrm{NaCl}$ in $50 \mathrm{mM}$ Tris-HCl buffer, $\mathrm{pH}$ 7.4) for $20 \mathrm{~min}$, and then incubated with the KLH-preabsorbed antiserum $(\alpha 1 \mathrm{C}-\mathrm{KLH}$, final dilution $1: 100)$ overnight at $4^{\circ} \mathrm{C}$. The blot was then incubated with biotinylated goat-antirat IgG and $\lg M(1: 400$ in TBS, American Qualex) for $1 \mathrm{hr}$, followed by biotin detection using an avidin-biotin amplification system (Vectastain ABC kit, Vector Lab.) for $1 \mathrm{hr}$. The blot was finally developed in a DAB system. Control blots were incubated with both anti- $(\alpha 1 C)$ and normal rat-sera that were preabsorbed with antigens: antiserum preabsorbed to a conjugate of $\mathrm{KLH}$ and Hemigrapsus $\mathrm{Rh}-1$ peptide $(\alpha 1 \mathrm{C}-\mathrm{KLH} / 1 \mathrm{C})$ and normal rat serum preabsorbed to KLH (normal serum-KLH).

\section{Opsin location in the cells (EM immunocytochemistry)}

The eyes were fixed with $4 \%$ paraformaldehyde, $0.5 \%$ glutaraldehyde and $4.5 \mathrm{mM} \mathrm{CaCl}_{2}$ in $0.1 \mathrm{M}$ sodium cacodylate buffer (CB, pH 7.3) for $1 \mathrm{hr}$ on ice, and stored overnight in $\mathrm{CB}$ at $4^{\circ} \mathrm{C}$. The eyes were then postfixed with the reduced osmium fixative $\left(1 \% \mathrm{OsO}_{4}\right.$ and $1.5 \%$ potassium ferrocyanide in $\mathrm{CB}$ ) for $30 \mathrm{~min}$ on ice (Tamaki and Yamashina, 1994). After being dehydrated through a graded methanol series, the eyes were embedded in L. R. White. Ultrathin sections were collected on nickel grids. The sections were first etched with saturated sodium metaperiodate for $3 \mathrm{~min}$, blocked with $4 \%$ bovine serum albumin (BSA) in $0.5 \mathrm{M} \mathrm{NaCl}$ plus $0.25 \%$ gelatin in sodium phosphate buffer (PBSG, pH 7.4) for $15 \mathrm{~min}$, and then incubated with the $\mathrm{KLH}$-preabsorbed antiserum $(\alpha 1 \mathrm{C}-\mathrm{KLH}$, final dilution 1:50-1:100) in $1 \%$ BSA in PBSG overnight at $4^{\circ} \mathrm{C}$. Reacted antiserum was detected by incubating the sections with goat-antirat IgG-conjugated 5 or $15 \mathrm{~nm}$-gold (final dilution 1:50, Ultragold) in PBSG, for $1 \mathrm{hr}$ at room temperature. For control labeling, both $\alpha 1 \mathrm{C}-\mathrm{KLH} / 1 \mathrm{C}$ and normal serum-KLH were used.

\section{Visualization of membrane structure (freeze-fracture EM)}

Retinal tissues were fixed with $2.5 \%$ glutaraldehyde in $0.1 \mathrm{M}$ sodium phosphate buffer $(\mathrm{pH} 7.3)$ for $4-5 \mathrm{hr}$ at $4^{\circ} \mathrm{C}$. After being washed and kept in the buffer overnight, the eyes were immersed in $35 \%$ glycerol for $3 \mathrm{hr}$ and then rapidly frozen in liquid nitrogen. The eyes were subsequently transferred to a JEOL freeze-fracture apparatus (JFD-7000) and fractured at $-120^{\circ} \mathrm{C}$ at $10^{-6}$ Torr. Immediately after fracturing by a razor blade, platinum vapor was deposited onto the fractured surface at an angle of $45^{\circ}$ followed by a carbon coating at $90^{\circ}$.

\section{RESULTS}

As in other decapod crustaceans, the ommatidium of the compound eye of $H$. sanguineus is furnished with eight photoreceptor cells (R1-8). R1-7 contribute their rhabdomeric microvilli to the rhabdom along almost its entire length, whereas R8 forms a small rhabdomere at the distal tip of the rhabdom. Among R1-7, R1 is twice the size of R2-7 in transverse section (Eguchi, 1965; Arikawa et al., 1987). All qualitative observations reported here were made on R1-7, whereas quantitative analyses were made on R2-7. Daily changes in ultrastructure of crab photoreceptor cells have already been documented to some extent (Stowe, 1980; Arikawa et al., 1987; Toh, 1990a). Therefore, we focus on the vesicles, which abundantly appear in the photoreceptor cell body around dusk, to characterize them, and also to reveal how they are incorporated into the rhabdom.

\section{Characterization of the vesicles}

Typical appearances of photoreceptor cell bodies sampled at various times of the day are shown in Fig. 1: 10:15 (midday, Fig. 1a, b), 15:15 (45 min before light-off, Fig. 1c), and 16:45 (45 min after light-off, Fig. 1d).

In the eye sampled at midday, the cell body contained some MVBs and lysosomal bodies, which both originated from the membrane breakdown after dawn (Fig. 1a). We frequently observed rough-surfaced endoplasmic reticulum ( $\mathrm{rER}$ ) with swollen cavity. The membranes of these swellings were free of ribosomes. In addition, we frequently observed Golgi complexes close to the swellings. The Golgi complexes almost always comprised irregularly vacuolized cisternae (Fig. 1b). 

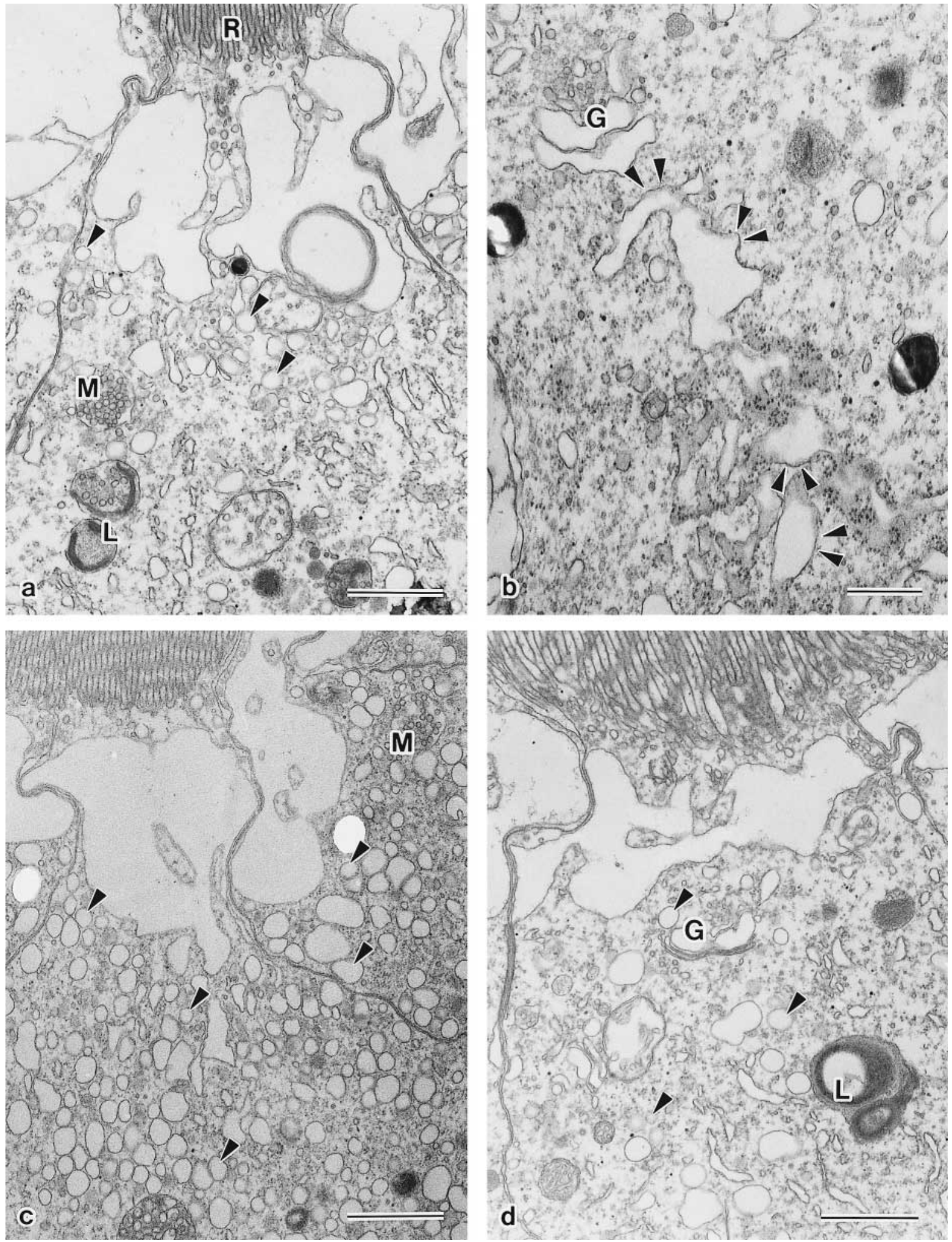

Fig. 1a-d. Electron micrographs of the photoreceptor cell body in the eye of $H$. sanguineus sampled at: (a, b) $10: 15$ (midday), (c) $15: 15$ (45 min before light-off), and (d) 16:45 (45 min after light-off). Vesicles are indicated by arrowheads in $\mathbf{a}, \mathbf{c}$ and $\mathbf{d}$. (a) The cell body still contained a few multivesicular bodies (M) and lysosomal bodies (L). (b) Rough-surfaced endoplasmic reticulum ( $\mathrm{rER}$ ) with swellings. Part of the membrane of swollen rER (arrowheads) is free of ribosome. (c) The cell body filled with the vesicles $(\varnothing=150-330 \mathrm{~nm}$, arrowheads). (d) Vesicles are now sparse in the cell body. R, rhabdom; G, Golgi complex. Bars; a, c, d $1 \mu \mathrm{m} ; \mathbf{b} 0.5 \mu \mathrm{m}$. 
In the last hour of the light period, the cell body was filled with vesicles (Fig. 1c), which correspond to the 'vesicular sER' we identified previously (Matsushita and Arikawa, 1996, 1997). Shortly before and after light-off, the cell body area close to the rhabdom contained many vesicles.

Fig. 1d shows a photoreceptor cell body sampled at 45 min after light-off. The vesicles are sparse in the cell body. The changes in rhabdom size and the number of vesicles per $1 \mu \mathrm{m}^{2}$ (numerical density) in the photoreceptor cell body (excluding the cytoplasmic bridge) over the day are shown in Fig. 2. The numerical density of vesicles begins to increase at around midday and reaches its maximum at approximately one hour before light-off. The density then begins to decrease and the vesicles almost disappear within the first hour after light-off. On the other hand, the rhabdom size begins to increase immediately after light-off. It seems that the vesicles are produced during the second half of the daytime and are incorporated into the rhabdomeric microvilli after light-off.

Given that the vesicles are rhabdomeric membrane precursors, the total number of vesicles in the cell body should reflect the increased amount of rhabdomeric membrane. We estimated the total amount of vesicular membrane in the cell

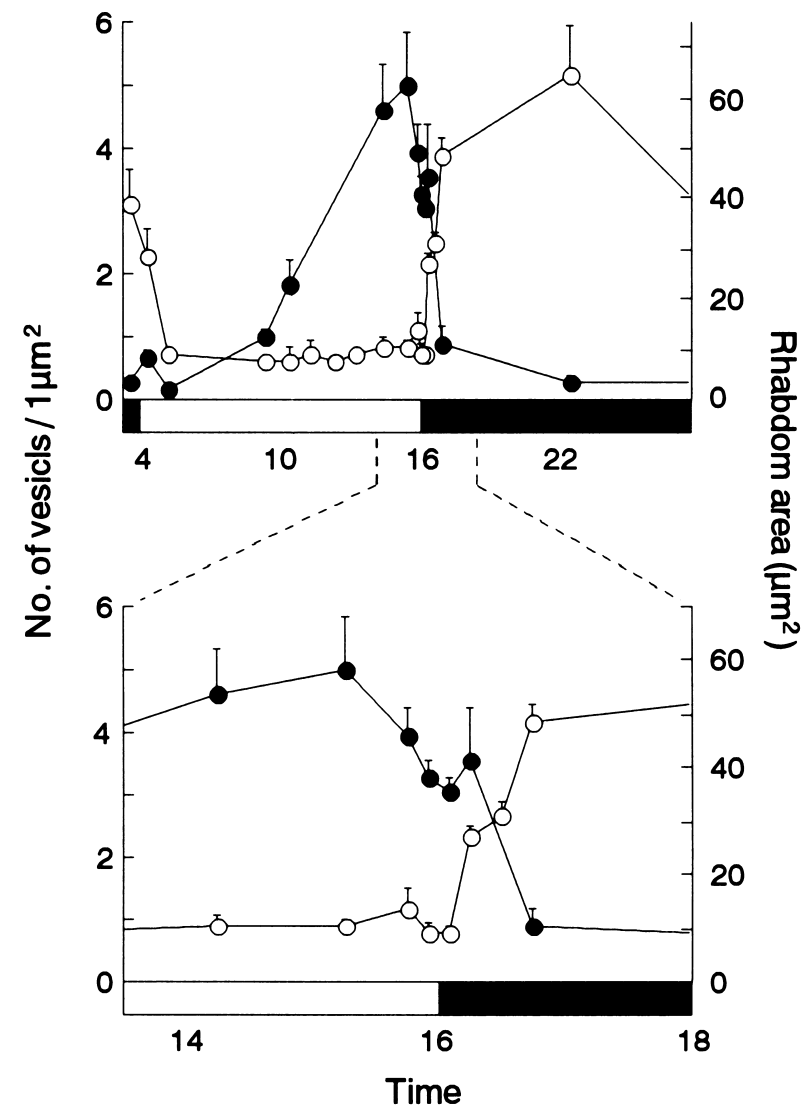

Fig. 2. Changes in the rhabdom area (mean \pm SE) and vesicle (mean \pm SE) numerical density in the cell body over a day (top). The changes around dusk are enlarged (bottom). Measurements were made on 320 ommatidia from 2-7 individuals for each sampling time. The numerical density of the vesicles was measured on electron micrographs of eight photoreceptors of four ommatidia. body and compared it with the increased amount of rhabdomeric membrane. Since the membrane surface area is roughly proportional to the length of membrane observed in sections, we measured the membrane length of both vesicles and rhabdomeric microvilli on electron micrographs. The average of the perimeter length of a single vesicle was $0.64 \mu \mathrm{m}$.

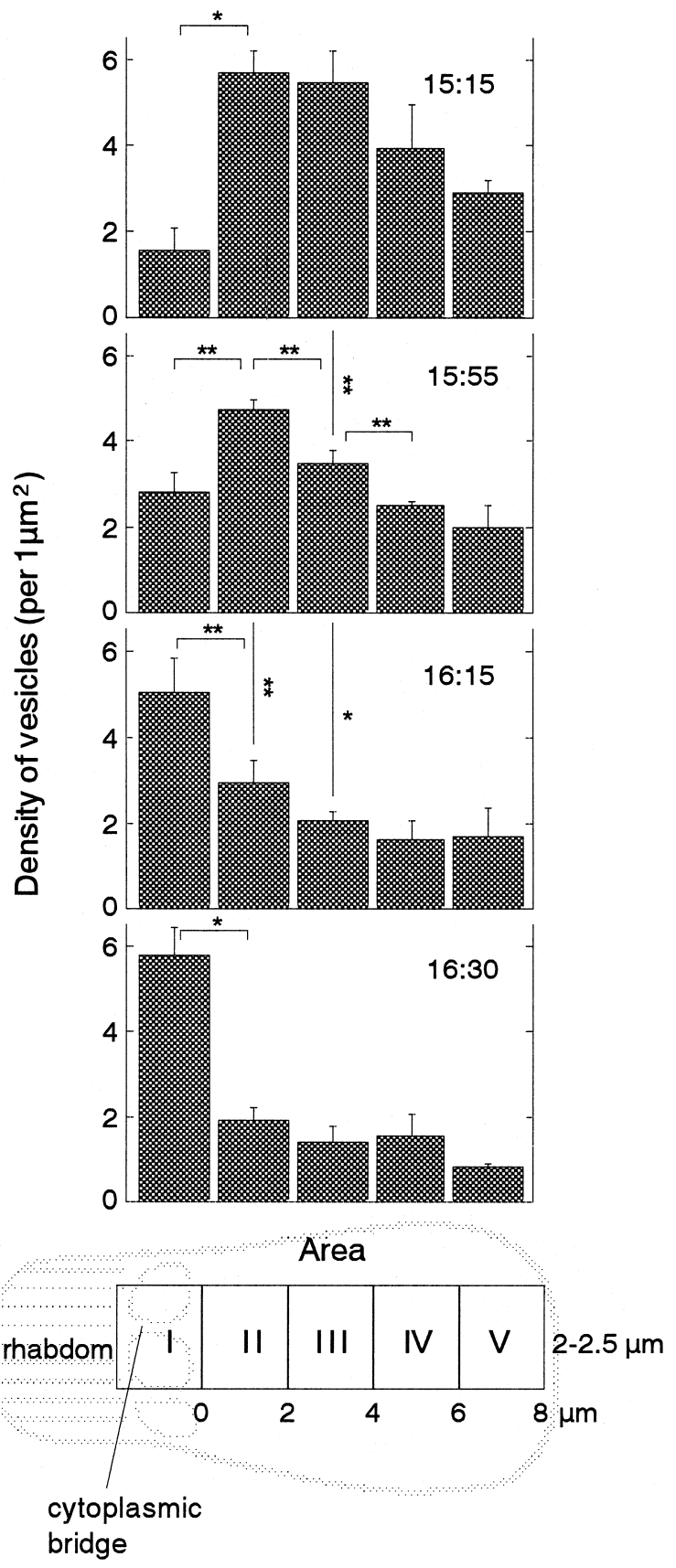

Fig. 3. Changes in the density of vesicles (mean \pm SE) in the cytoplasmic bridge (area I) and each framed area (areas II-V) of a transversely sectioned photoreceptor cell body. Light was turned off at 16:00. Note that, between 15:55 and 16:15, the vesicle densities significantly decrease in both areas II and III whereas the density in the area I reciprocally increases. Measurements were made on 3-62 photoreceptor cells from $2-8$ individuals. ${ }^{*}, p<0.01 ;{ }^{* *}, p<0.05$ (Student's $t$-test) 
There were 5.01 vesicles per $1 \mu \mathrm{m}^{2}$ (cell body area $=34.6$ $\mu \mathrm{m}^{2}$ ) when the density was at the maximum (15:00, Fig. 2), so that the sum total of the vesicle perimeter was calculated to be approximately $111 \mu \mathrm{m}$. Note that this figure assumes no incorporation of vesicles during vesicle synthesis: it is actually a minimum estimate of synthesized membrane. The calculation for the increase in length of the microvillar membrane indeed produced the larger figure of $192 \mu \mathrm{m}$. The membrane deficit of $81 \mu \mathrm{m}$ may be accounted for the vesicles synthesized after 15:00 when the density of vesicles starts to decrease: the synthesis of vesicles and their incorporation into the rhabdom most likely occur simultaneously.

To assess whether the vesicles indeed move from the cell body toward the rhabdom, we measured the numerical density of vesicles in different areas of the cell body. In electron micrographs of transverse sections of the cell body, we first defined five rectangular areas of $2 \mu \mathrm{m}$ by $2-2.5 \mu \mathrm{m}$ (areas $\mathrm{I}-\mathrm{V})$ as shown in Fig. 3. For area I over the cytoplasmic bridge, the density was calculated for the bridge excluding the surrounding vacuole. During 20 min around light-off, i. e., from $15: 55$ to $16: 15$, the density significantly decreased in both areas II and III, whereas the density significantly increased in area I (Fig. 3).

L. R. White sections were examined for the distribution of gold particles, which represent the presence of opsin. Gold particles were found on the rhabdom, MVB, and the vesicles (Fig. 4a-c). Table 1 summarizes the labeling results. The percentages in both the rhabdom and the MVB are higher than
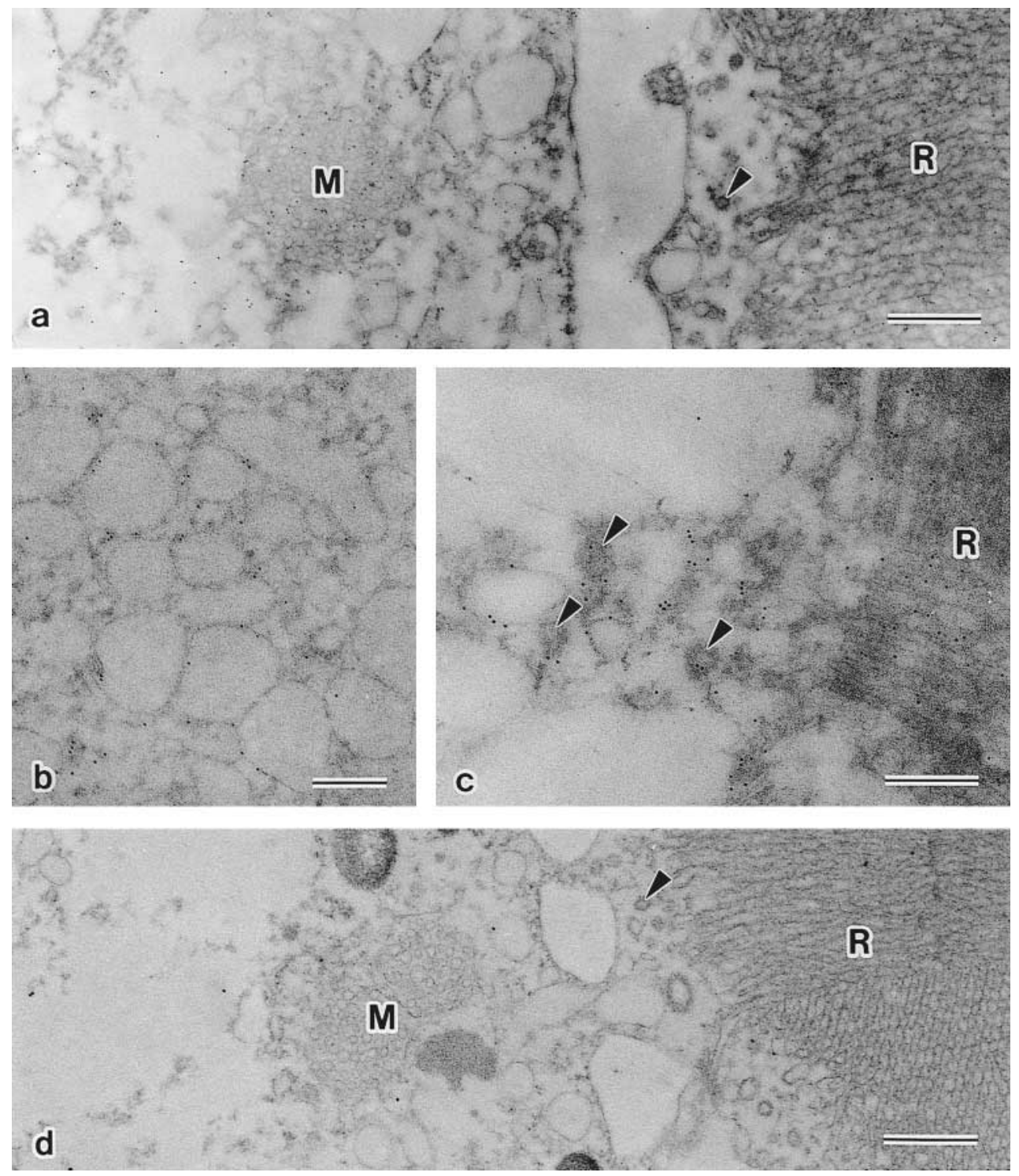

Fig. 4a-d. Antiopsin immunocytochemistry of the eyes at 20 min after light-off. (a-c) Antiopsin labeling incubated with KLH-preabsorbed antiserum $(\alpha 1 \mathrm{C}-\mathrm{KLH})$. (a) Longitudinal view of a photoreceptor cell. Antiopsin densely labeled the rhabdom (R) and multivesicular body (M). (b) Vesicles in the cell body close to the rhabdom. Note that $5 \mathrm{~nm}$ particles are detected on the vesicle membranes. (c) Vesicles and coated vesicles (arrowheads) in the cytoplasmic bridge. (d) Control labeling incubated with KLH-preabsorbed normal serum. Both the rhabdom and multivesicular body are not labeled. Bars: a $0.5 \mu \mathrm{m}$; b $0.2 \mu \mathrm{m}$; c $0.2 \mu \mathrm{m}$; d $0.5 \mu \mathrm{m}$. Arrowheads indicate coated vesicles. 
Table 1. Comparison of the density of the antiopsin labeling. Area without vesicles includes rER as well as cytosol. Data were obtained from both labeling with $5 \mathrm{~nm}$ and $15 \mathrm{~nm}$ gold particles. Data were obtained from 2 individuals.

\begin{tabular}{rc}
\hline Region & $\begin{array}{c}\text { Ratios of gold particle in each region to } \\
\text { total number of the particle (\%) }\end{array}$ \\
\hline $\begin{array}{r}\text { rhabdom } \\
\text { multivesicular body }\end{array}$ & 31.7 \\
cell body region with vesicles & 35.6 \\
cell body region without vesicles & 21.9 \\
\hline
\end{tabular}

elsewhere. Besides the rhabdoms and MVBs, the region filled with vesicles is more densely labeled than regions without vesicles. In negative control labeling, where we used preabsorbed antisera, accumulation of gold particles was negligible in all areas (Fig. 4d).

Specificity of the antiopsin was confirmed by immunoblot analysis: the antiserum preabsorbed to KLH detected a rather broad band with molecular weight $\sim 35 \mathrm{kD}$. The reason for the broadness may be that the band represents immature Rh-1 opsins in addition to mature ones: the process of post-translational modification often alters the molecular weight of opsins (Fig. 5, Ozaki et al., 1993; Katanosaka et al., 1998).

\section{$\begin{array}{llll}1 & 2 & 3 & 4\end{array}$}

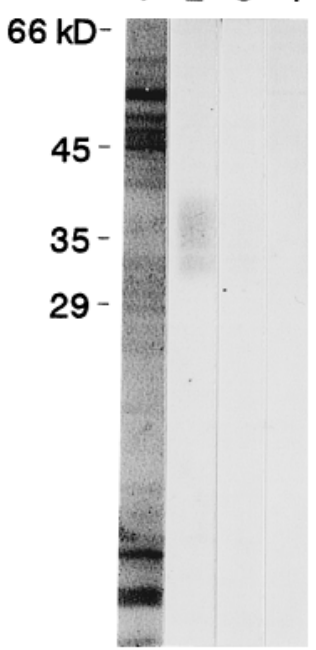

Fig. 5. Immunoblot of proteins from retinal homogenate of $H$. sanguineus. Each lane contains the same amount of protein. Electrophoretically separated retinal homogenate was transferred to a PVDF. Lane 1, The PVDF transblot stained with coomassie brilliant blue. Lane 2, 3 and 4, The PVDF transblot incubated with: $\alpha 1 \mathrm{C}-\mathrm{KLH}$ (Lane 2); $\alpha 1 \mathrm{C}-\mathrm{KLH} / 1 \mathrm{C}$ (Lane 3); normal serum-KLH (Lane 4). Numbers on the left indicate molecular weight.

Freeze-fracture EM indicated that the vesicles bear intramembranous particles with diameters ranging 9-11 nm, which are similar to the particles found in the rhabdomeric membranes (Arikawa et al., 1987). The density of the particles on the concave protoplasmic face (P-face) of the vesicle was approximately $550 / \mu^{2}$ (Fig. 6): the value was much lower than that in the rhabdomeric membranes $\left(2000 / \mu \mathrm{m}^{2}\right.$, Arikawa

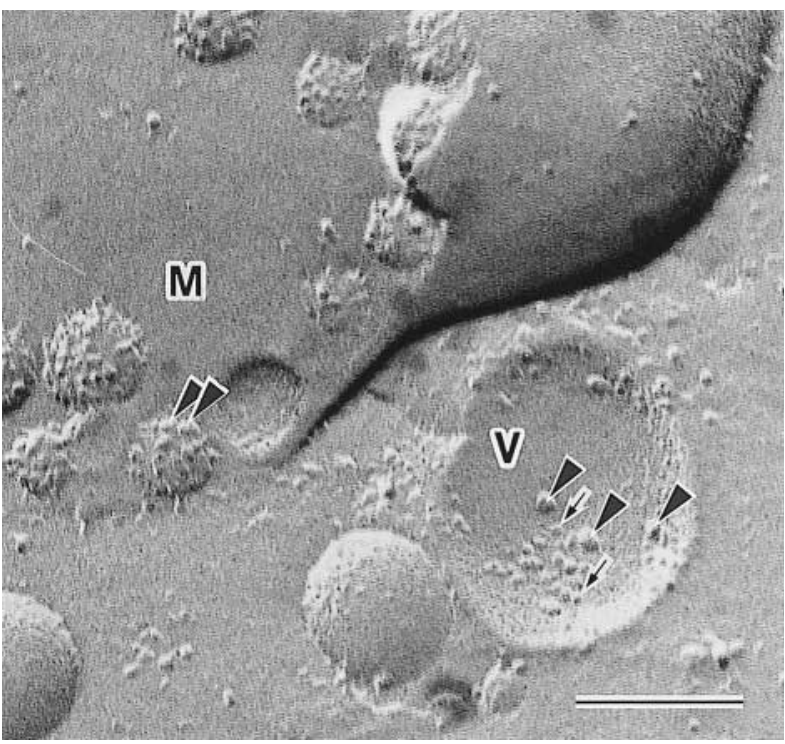

Fig. 6. A vesicle (V) and a multivesicular body (M) from freeze-fractured photoreceptor. The concave P-face of the vesicle has a low density intramembranous particles (arrowheads) compared to the multivesicular body. The membrane of the vesicle contained smaller particles with diameter of approximately $5 \mathrm{~nm}$ (arrows), which may represent single rhodopsin molecules. Bar: $0.1 \mu \mathrm{m}$.

et al., 1987). Judging from the diameter, Eguchi et al. (1989) concluded that a single particle is an aggregate of four rhodopsin molecules.

\section{Ultrastructure of the cytoplasmic bridge and the perirhabdomeric cytoplasm}

Fig. 7 shows ultrastructural changes in the cytoplasmic bridge and the perirhabdomeric cytoplasm (PRC) during the first one hour after light-off, the period when the rhabdom accretion is taking place.

The PRC of the photoreceptor cells immediately after lightoff (16:05) is characterized by a transient increase in the number of coated vesicles (Fig. 8). The coated vesicles are formed by pinocytosis at the microvillar base (Fig. 7a). These vesicles were frequently observed in the cytoplasmic bridge (Fig. 7ac). Protrusions of vesicles in the PRC and in the cytoplasmic bridge were also observed (Fig. 7b, c).

In the first quarter of an hour after light-off (16:05 - 16:15), the PRC contains many smaller vesicles with diameter of 110.4 $\pm 10.2 \mathrm{~nm}$ (mean \pm SE, ranging $60-150 \mathrm{~nm}$, Fig. 7c, d). These are approximately half the size of those that had occupied the 

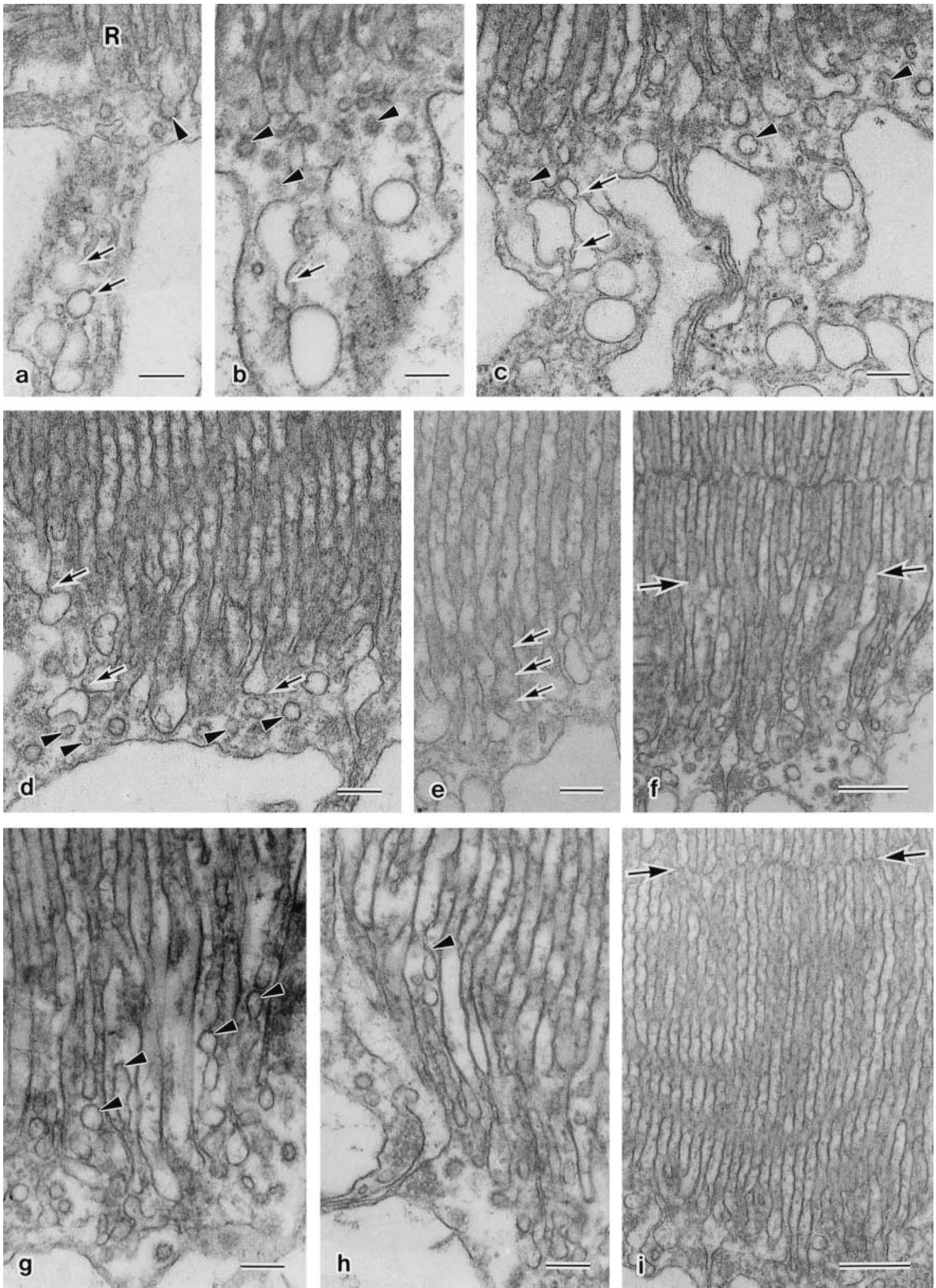

Fig. 7a-i. Ultrastructural changes in the perirhabdomeric cytoplasm (PRC). (a-c) Immediately before and after light-off, (d-h) 15 min after lightoff, (i) 30 min after light-off. (a) Pinocytotic pit (arrowhead) formed at the microvillar base. Vesicles (arrows) are observed within the cytoplasmic bridge. (b, c) Coated vesicles (arrowheads) in the PRC. Protrusion of vesicles (arrows) in the cytoplasmic bridge. (d) Vesicles ( $\varnothing=150-330 \mathrm{~nm}$ ), and small vesicles (arrowheads, $\varnothing=60-150 \mathrm{~nm}$ ) in the PRC. Some appear to fuse with the microvillar base (arrows). (e) Elongated stem (arrows). (f) The rhabdom with a loose periphery. Arrows indicate a boundary between tightly packed microvillar part and the loose part. (g) Small vesicles and tubules in the elongated stem (arrowheads). (h) A small vesicle fusing to the proximal tip of the microvilli (arrowhead). (i) The loose membrane is restricted only to the base of the microvilli. The distal tips of the microvilli are indicated by arrows. Bars: $\mathbf{a}-\mathbf{e} 0.2 \mu \mathrm{m} ; \mathbf{f} 0.5 \mu \mathrm{m} ; \mathbf{g}, \mathbf{h}$ $0.2 \mu \mathrm{m} ; \mathbf{i} 0.5 \mu \mathrm{m}$. 


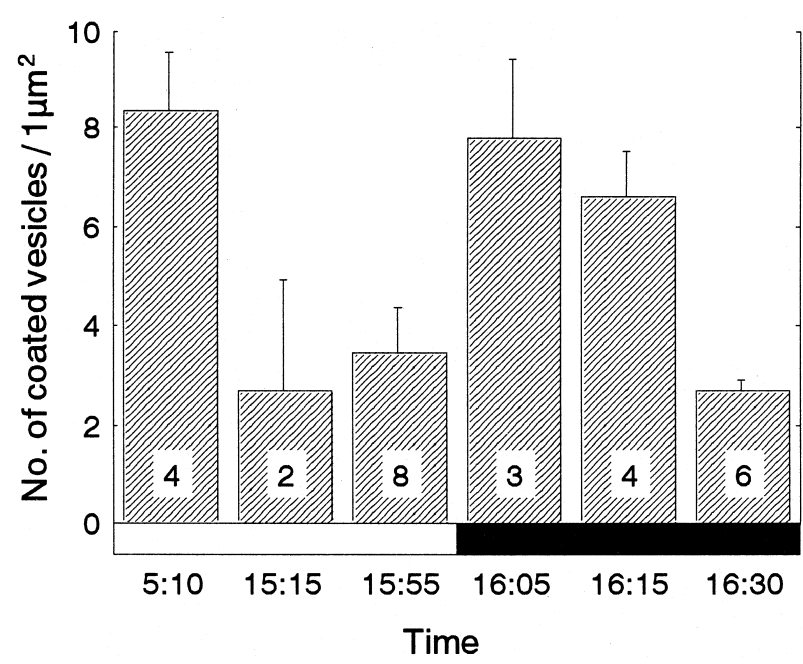

Fig. 8. Changes in density of coated vesicles in the perirhabdomeric cytoplasm. Numbers in the column represent the number of individuals used. Density of coated vesicles transiently increases immediately after light-off (16:05). Bars represent standard errors.

cell body before light-off ( $\varnothing=208.7 \pm 25.6 \mathrm{~nm}$, ranging 150 $330 \mathrm{~nm}$; Fig, 1c). For convenience, we hereafter refer to the vesicles with diameters of $60-150 \mathrm{~nm}$ as 'small' vesicles to discriminate them from the vesicles with diameters of 150 $330 \mathrm{~nm}$. Both types of vesicles fuse to a base-like structure that is shared by several microvilli. The structure is called 'stem' and commonly found in crustacean species: e.g. shrimp, (Itaya, 1976); mantis shrimp (King and Cronin, 1993); crabs, (Eguchi and Waterman, 1967; Nässel and Waterman, 1979; Toh and Waterman, 1982; Toh, 1987). Further fusion of vesicles makes the stems elongate in the direction of the cell body (Fig. 7e).

In eyes with a little enlarged rhabdoms, e.g. in the eyes fixed at 15 min after light-off, we frequently found that the peripheral part of the rhabdom in transverse section appeared somewhat loose, whereas the central part was tightly packed (Fig. 7f). The loose part of the rhabdom corresponds with the stem elongation, because the size of the tightly packed part of the rhabdom was the same as that of the rhabdom immediately before light-off (Fig. 9). Within the stem, tubules and/or small vesicles were observed (Fig. $7 \mathrm{~g}$ ). These appeared to fuse to the proximal tip of the microvilli (Fig. $7 \mathrm{~h}$ ).

In the latter half of the hour after light-off (16:30 - 17:00), the loose membranes were found only in the rhabdom base where the addition of membranes to the microvilli was still taking place. The length of the tightly packed microvilli became longer due to further fusion of the tubules and/or small vesicles at the proximal tip of the microvilli (Figs. 7i, 9).

All rhabdoms observed in the present study appeared to have a modal arrangement of microvilli. This contrasts with previous observations in Leptograpsus, where the whole rhabdom was noted to first degrade before being rapidly reconstructed after light-off (Stowe, 1980).

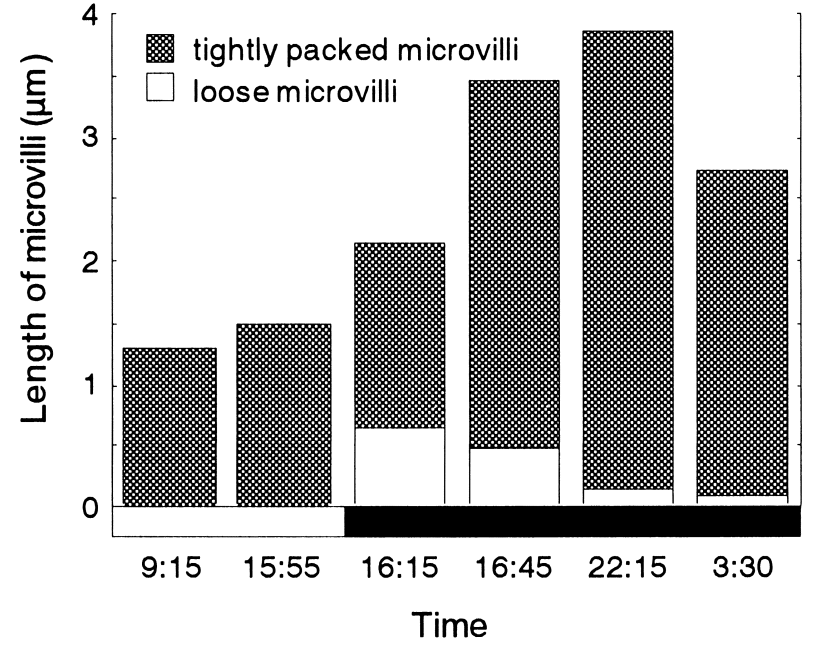

Fig. 9. Changes in length of the tightly packed microvilli (hatched) and the loose microvilli (white).

\section{DISCUSSION}

\section{Vesicles as precursors of the rhabdom}

In the present study, we conclude that the vesicles are the precursors of the rhabdomeric membrane based on the following evidence. (1) The number of vesicles increases in the late light period and decreases around dusk, and the decrease around dusk is accompanied by a reciprocal increase in rhabdom size. (2) The vesicles contain the visual pigment opsin as an integral membrane protein.

The vesicles are prepared in the cell body during the light period. This conclusion agrees with interpretations of previous experiments in which the light is abruptly turned off within the subjective day: the later the light is turned off, the faster the rhabdom size reaches the normal night level (Stowe, 1981; Arikawa et al., 1988).

Arikawa et al. (1987) showed that the amount of rER increased in the late light period. In addition, as shown previously (Itaya, 1976; Stowe, 1980), vesicles are formed by transformation of the rER (Fig. 1b). Combined with the present result that the vesicle contains the visual pigment opsin, this indicates that the opsin is synthesized in rER in parallel with the formation of vesicles. As was found in $\mathrm{H}$. penicillatus (Toh, 1990a), we frequently observed a Golgi complex with irregularly vacuolized cisternae localized close to the rER. In Drosophila, when vesicular transport between rER and Golgi complex is genetically blocked, swollen rER accumulates in the photoreceptors (Satoh et al., 1997). Thus, the Golgi complex may also be involved in the formation of the vesicles.

The densities of both antiopsin immunolabeling and the intramembranous particles seem lower in the vesicles compared to those in the rhabdom and MVB (Figs. 4, 6 and Table 1). This indicates a relatively low density of opsin molecules in the vesicles. The opsins may be concentrated when the vesicles are incorporated into the rhabdom by removal of opsin-free membrane from it. If so, the calculated $81 \mu \mathrm{m}$ deficit 
of membrane (see Results) is a severe underestimate of the actual amount of membrane synthesized. However, it is actually hard to determine the exact amount of vesicular membrane synthesized around light off, because both synthesis of vesicles and their incorporation to the rhabdom are taken place during this period (Matsushita and Arikawa, 1997).

The vesicles are indeed transported toward the rhabdom (Fig. 3). The movement of the vesicles within the cell body is actin-dependent (Matsushita and Arikawa, 1996, 1997) as was also reported for Drosophila blastoderm cells (Sullivan and Theurkauf, 1995) and for Saccharomyces (Hill et al., 1996). However, it is still uncertain whether the incorporation of the vesicles into the rhabdom is actin-dependent too, but application of the actin inhibitor cytochalasin D could not disrupt the actin filament organization in the immediate vicinity and inside of rhabdom (Matsushita and Arikawa, 1996).

\section{How do the microvilli elongate?}

To increase the rhabdom volume, the rhabdomeric microvilli must elongate toward the cell body. The addition of new membranes occurs in the PRC. Fig. 10 summarizes our model for this process, which is divided into four steps.

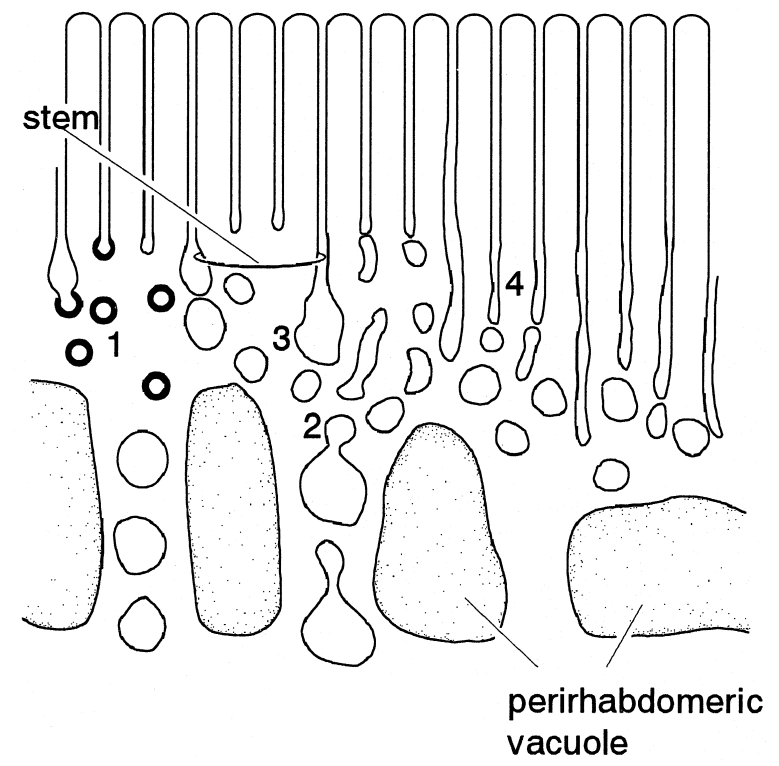

Fig. 10. Schematic representation of the proposed pathway of how the rhabdomeric microvilli elongate. Time advances from left to right. Numbers correspond to the steps 1-4 in the text.

Shortly after light-off, pinocytosis occurs at the microvillar base (step 1, Fig. 8). Usually pinocytosis involves a shortening of microvilli by shedding of membrane. The shed membranes, i. e., pinocytotic vesicles, then assemble to form MVBs (Arikawa et al., 1987; Stowe et al., 1990). In the case of the crab photoreceptor cell, the microvilli are shortened at dawn (Fig. 8), and thus many MVBs appear in the cell body at this time (Arikawa et al., 1987). Also at dusk, the photoreceptor cells show transient increase in number of MVBs (Arikawa et al., 1987). This is a phenomenon probably related to the pin- ocytosis at the microvillar base (Figs. 7a-c, 8). However, the microvilli do not shorten around dusk, suggesting that the pinocytosis around dusk has a different function. Although the exact function is still unknown, the pinocytosis around dusk may be necessary for making the region prepared for following incorporation of new membranes. Or, it may remove excess membrane for rhodopsin concentration in the rhabdoms (see Fig. 6).

In step 2, the vesicles migrate from the cell body into the PRC through the cytoplasmic bridge. In the PRC and the cytoplasmic bridges, some of the vesicles divide to form smaller vesicles (Fig. 7b, c).

Step 3 involves actual addition of membranes to the rhabdom. The vesicles, including the small vesicles formed in step 2 , fuse to the stem bases. The stems continue to elongate by further fusion of vesicles, enlarging the 'loose' part of the rhabdom.

In step 4, the tubules and/or small vesicles migrate into the stem and fuse to the proximal tip of the microvillar membrane, making all microvilli longer. Finally, when the elongation of the microvilli has almost completed (Fig. 7i), the basal part of each microvillus is tightly packed, indicating that reorganization of a core in the microvillus occurs in parallel with microvillar elongation (Arikawa et al., 1990).

\section{ACKNOWLEDGEMENTS}

We thank Dr. W. van der Goes van Naters and Dr. D. G. Stavenga (University of Groningen) for critical reading of the manuscript, and Dr. K. Ozaki (Osaka University) and Dr. Y. Fukada and Dr. T. Okano (University of Tokyo) for helpful discussions. The KLH-conjugated opsin Rh-1 polypeptide was a generous gift from Dr. K. Sakamoto. The work was supported by grants from the Uehara Memorial Foundation to K. Arikawa and the Ministry of Education, Science, and Culture of Japan to K. Arikawa and E. Eguchi.

\section{REFERENCES}

Arikawa K, Hicks JL, Williams DS (1990) Identification of actin filaments in the rhabdomeral microvilli of Drosophila photoreceptors. J Cell Biol 110: 1993-1998

Arikawa K, Kawamata K, Suzuki T, Eguchi E (1987) Daily changes of structure, function and rhodopsin content in the compound eye of the crab Hemigrapsus sanguineus. J Comp Physiol A 161: $161-174$

Arikawa K, Morikawa Y, Suzuki T, Eguchi E (1988) Intrinsic control of rhabdom size and rhodopsin content in the crab compound eye by a circadian biological clock. Experientia 44: 219-220

Barlow RB, Jr., Chamberlain SC, Levinson JZ (1980) Limulus brain modulates the structure and function of the lateral eyes. Science 210: 1037-1039

Blest AD (1980) Photoreceptor membrane turnover in arthropods: comparative studies of breakdown processes and their implications. In "The effects of constant light on visual processes" Ed by TP Williams and BN Baker, Plenum, New York, pp 217-245

Blest AD (1988) The turnover of phototransductive membrane in compound eyes and ocelli. Adv Insect Physiol 20: 1-53

Blest AD, Stowe S (1997) A phospholipase inhibitor, manoalide, and a G-protein activator, Mas-7, both affect the turnover of phototransductive membranes by crab retinas in darkness. $J$ Comp Physiol A 180: 347-355 
Blest AD, Stowe S, Delaney A (1993) Diacylglycerols as putative second messengers that regulate phototransductive membrane turnover by arthropods. J Comp Physiol A 173: 57-63

Eguchi $E$ (1965) Rhabdom structure and receptor potentials in single crayfish retinular cells. J Cell Comp Physiol 66: 411-430

Eguchi E, Seki T, Suzuki T (1989) Comparative studies of chromophore contents inside and outside the rhabdoms of arthropod compound eyes. J Comp Physiol A 165: 589-604

Eguchi E, Waterman TH (1967) Changes in retinal fine structure induced in the crab Libinia by light and dark adaptation. Z Zellforch 79: 209-229

Eguchi E, Waterman TH (1976) Freeze-etch and histochemical evidence for cycling in crayfish photoreceptor membranes. Cell Tissue Res 169: 419-434

Hill KL, Catlett NL, Weisman LS (1996) Actin and myosin function in directed vacuole movement during cell division in Saccharomyces cerevisiae. J Cell Biol 135: 1535-1549

Huber A, Wolfrum U, Paulsen R (1994) Opsin maturation and targeting to rhabdomeral photoreceptor membranes requires the retinal chromophore. Eur J Cell Biol 63: 219-229

Itaya SK (1976) Rhabdom changes in the shrimp, Palaemonetes. Cell Tissue Res 166: 265-273

Katanosaka K, Tokunaga F, Kawamura S, Ozaki K (1998) N-linked glycosylation of Drosophila rhodopsin occurs exclusively in the amino-terminal domain and functions in rhodopsin maturation. FEBS Lett 424: 149-154

King CA, Cronin TW (1993) Cytoskeleton of retinular cells from the stomatopod, Gonodactylus oerstedii: possible roles in pigment granule migration. Cell Tissue Res 274: 315-328

Laemmli UK (1970) Cleavage of structural proteins during the assembly of the head of bacteriophage T4. Nature 227: 680-685

Matsushita A, Arikawa K (1996) Disruption of actin filament organization by cytochalasin $D$ inhibits rhabdom synthesis in the compound eye of the crab Hemigrapsus sanguineus. Cell Tissue Res 286: $167-174$

Matsushita A, Arikawa K (1997) Actin-based vesicular transport in the first 20 min after dusk is crucial for daily rhabdom synthesis in the compound eye of the grapsid crab Hemigrapsus sanguineus. J Exp Biol 200: 2387-2392

Nässel DR, Waterman TH (1979) Massive diurnally modulated photoreceptor membrane turnover in crab light and dark adaptation. J Comp Physiol A 131: 205-216

Ozaki K, Nagatani H, Ozaki M, Tokunaga F (1993) Maturation of major Drosophila rhodopsin, ninaE, requires chromophore 3hydroxyretinal. Neuron 10: 1113-1119

Robles LJ, Cabebe CS, Aguilo JA, Anyakora PA, Bok D (1984) Autoradiographic and biochemical analysis of photoreceptor membrane renewal in Octopus retina. J Neurocytol 13: 145-164

Sakamoto K, Hisatomi O, Tokunaga F, Eguchi E (1996) Two opsins from the compound eye of the crab Hemigrapsus sanguineus. J Exp Biol 199: 441-450

Satoh AK, Tokunaga F, Kawamura S, Ozaki K (1997) In situ inhibition of vesicle transport and protein processing in the dominant negative Rab1 mutant of Drosophila. J Cell Sci 110: 2943-2953
Schwemer J (1985) Turnover of photoreceptor membrane and visual pigment in invertebrates. In "The molecular mechanism of photoreception" Ed by H Stieve, Springer-Verlag, Berlin, Heidelberg, New York, Tokyo, pp 303-326

Stark WS, White RH (1996) Carotenoid replacement in Drosophila: freeze-fracture electron microscopy. J Neurocytol 25: 233-241

Stowe S (1980) Rapid synthesis of photoreceptor membrane and assembly of new microvilli in a crab at dusk. Cell Tissue Res 211: 419-440

Stowe S (1981) Effects of illumination changes on rhabdom synthesis in a crab. J Comp Physiol A 142: 19-25

Stowe S, De Couet HG, Davis D (1990) Photoreceptor membrane turnover in the crayfish Cherax destructor: electron microscopy and anti-rhodopsin electron-microscopic immunocytochemistry. Cell Tissue Res 262: 483-499

Sullivan W, Theurkauf WE (1995) The cytoskeleton and morphogenesis of the early Drosophila embryo. Curr Opin Cell Biol 7: 18-22

Suzuki E, Hirosawa K (1991) Immunoelectron microscopic study of the opsin distribution in the photoreceptor cells of Drosophila melanogaster. J Electron Microsc 40: 187-192

Tamaki H, Yamashina S (1994) Improved method for post-embedding cytochemistry using reduced osmium and LR White resin. J Histochem Cytochem 42: 1285-1293

Toh Y (1987) Diurnal changes of rhabdom structures in the compound eye of the grapsid crab, Hemigrapsus penicillatus. J Electron Microsc 36: 213-223

Toh Y (1990a) Diurnal changes in the cytoplasmic organelles of the retinular cell in the compound eye of the grapsid crab, Hemigrapsus penicillatus. J Electron Microsc 39: 492-500

Toh Y (1990b) Diurnal structural changes in rhabdomeric microvilli of the compound eye in the blue crab, Callinectes sapidus. Zool Sci 7: 961-965

Toh Y, Waterman TH (1982) Diurnal changes in compound eye fine structure in the blue crab Callinectes. I. Differences between noon and midnight retinas on an LD 11:13 cycle. J Ultrastruct Res 78: 40-59

Waterman TH (1982) Fine structure and turnover of photoreceptor membranes. In "Visual cells in evolution" Ed by JA Westfall, Raven Press, New York, pp 23-41

White $\mathrm{RH}$ (1967) The effect of light and light deprivation upon the ultrastructure of the larval mosquito eye. II. The rhabdom. J Exp Zool 166: 405-426

White RH, Bennet RR (1992) Assembly of rhabdomeric membrane from smooth endoplasmic reticulum can be activated by light in chromophore-deprived photoreceptors of Manduca sexta. Cell Tissue Res 270: 65-72

Williams DS, Blest AD (1980) Extracellular shedding of photoreceptor membrane in the open rhabdom of a tipulid fly. Cell Tissue Res 205: 423-438

(Received April 17, 1998 / Accepted October 21, 1998) 